\title{
Analysis of Indications for Electrotherapy Using Classification Trees
}

\author{
Roman Załuska ${ }^{1,3}$, Anna Justyna Milewska ${ }^{2}$, Joanna Olszewska ${ }^{3}$, \\ Wojciech Drygas ${ }^{4}$
}

1 Department of Management and Logistics in Health Care, Medical University of Lodz, Poland

2 Department of Statistics and Medical Informatics, Medical University of Bialystok, Poland

3 Department of Cardiology, Mazovian Specialized Hospital of Ostroleka, Poland

4 Department of Epidemiology, Cardiovascular Disease Prevention and Health Promotion, Institute of Cardiology, Warsaw, Poland

\begin{abstract}
Electrotherapy is a dynamically developing method of treatment of sinus node dysfunction and atrioventricular conduction disturbances. It is an extremely important method used in the treatment of heart failure. The aim of this paper was to use classification trees for the differentiation between patients implanted with one of the three electrotherapy devices, i.e. SC-VVI/AAI, DC-DDD, ICD/CRT. The analysed data concerned 2071 patients who underwent implantation or device replacement procedures in the years 2010-2018, hospitalized in a coronary care unit. CART-type classification trees with 5-fold cross-validation were used for the analysis. The decision concerning the choice of a particular electrotherapy device is always made based on the latest guidelines and the patient's clinical condition. The used classification trees may enable verification of the state of implementation of guidelines in real-life therapeutic decisions.
\end{abstract}

\section{Introduction}

Heart electrotherapy is an established method of treatment of atrioventricular conduction disturbances and sinus node dysfunction. The role of the implantable cardioverter-defibrillator (ICD) in the prevention of sudden cardiac death is hard to overestimate. Cardiac resynchronisation therapy (CRT) is a state-of-the-art technique that modifies the course of chronic heart failure, significantly improving prognosis (Ponikowski et al., 2016). The technologies have for many years been in a state of dynamic development. The devices undergo miniaturization while the software makes it 
possible to constantly improve the adaptation of stimulation to the patient's individual needs. Heart electrotherapy devices also provide many possibilities of analysis of the heart rhythm, owing to the recording of intracardiac electrograms.

The most common indications for continuous cardiac stimulation are high degree AV block and sick sinus syndrome (SSS). Such a course of action improves the prognosis (in the case of AV block) and the quality of life (in the case of sick sinus syndrome) of patients treated with this method. The introduction of the implantable cardioverter-defibrillator was a breakthrough in primary and secondary prevention of cardiac arrest. The constant development of cardiac resynchronization therapy (CRT/CRTD) gives hope for further improvement of prognosis in chronic heart failure.

Indications for device implantation are gradually extended together with the development of medical knowledge and technological improvements. Detailed guidelines from scientific societies are extremely useful in everyday practice of medical doctors specializing in the diseases in question.

Single chamber (SC) devices are systems in which a single electrode is implanted into the right atrium (AAI devices) or the right ventricle (VVI). Dual chamber (DC) devices require the use of two electrodes, one implanted into the right atrium, the other into the right ventricle (DDD). In the case of ICD devices, depending on the indications, single-electrode (in atrial fibrillation) or dual-electrode (in dominant sinus rhythm) devices are used. The cardiac resynchronization therapy CRT) device is a tripleelectrode device (right atrium, coronary sinus, and right ventricle). A cardiac resynchronization device may also perform the function of a cardioverterdefibrillator (CRTD). Electrodes of the implanted devices are connected to a power generator usually located underneath the chest muscle under the clavicle (Mulpuru et al., 2017).

Table 1 presents categories of recommendations and a description of the levels of evidence, which enable to interpret the guidelines correctly. Table 2 summarizes the indications for using the individual electrotherapy techniques, while Table 3 contains a selection of the modes of stimulation.

Table 1. Classes of recommendations and levels of evidence (Brignole et al., 2013)

\begin{tabular}{|c|l|l|}
\hline Class & \multicolumn{1}{|c|}{ Definition } & \multicolumn{1}{|c|}{ Suggestion } \\
\hline I & $\begin{array}{l}\text { Evidence from scientific studies show that the given } \\
\text { course of action is useful and effective }\end{array}$ & $\begin{array}{l}\text { Course of action } \\
\text { recommended }\end{array}$ \\
\hline IIa & $\begin{array}{l}\text { Evidence or opinions mostly point to the usefulness of } \\
\text { the therapy }\end{array}$ & Should be considered \\
\hline
\end{tabular}




\begin{tabular}{|c|l|l|}
\hline Class & \multicolumn{1}{|c|}{ Definition } & \multicolumn{1}{c|}{ Suggestion } \\
\hline IIb & $\begin{array}{l}\text { The usefulness of the method or the effectiveness of the } \\
\text { therapy is less well confirmed by studies or opinions }\end{array}$ & May be considered \\
\hline Level of evidence \\
\hline A & Data sourced from numerous randomized trials or metaanalyses \\
\hline B & Data sourced from a single randomized trial or large non-randomized trials \\
\hline C & $\begin{array}{l}\text { Expert opinion and/or other data sourced from small trials, retrospective } \\
\text { studies, or registers }\end{array}$ \\
\hline
\end{tabular}

Table 2. Indications for continuous cardiac stimulation, implantation of an implantable cardioverter-defibrillator and cardiac resynchronization devices (Brignole et al., 2013)

\begin{tabular}{|c|c|c|}
\hline & $\begin{array}{l}\text { Class of } \\
\text { recommendation }\end{array}$ & $\begin{array}{l}\text { Level of } \\
\text { evidence }\end{array}$ \\
\hline \multicolumn{3}{|c|}{ Indications for constant stimulation in patients with sustained bradycardia } \\
\hline $\begin{array}{l}\text { Sick sinus syndrome (SSS) when the symptoms are } \\
\text { connected to bradycardia }\end{array}$ & I & $\mathrm{B}$ \\
\hline $\begin{array}{l}\text { Sick sinus syndrome (SSS) when there is a probability } \\
\text { that the symptoms are connected to bradycardia even } \\
\text { when the evidence is not conclusive }\end{array}$ & $\mathrm{IIb}$ & $\mathrm{C}$ \\
\hline Acquired AV block III regardless of the symptoms & I & $\mathrm{C}$ \\
\hline Acquired AV block II t.2 regardless of the symptoms & I & $\mathrm{C}$ \\
\hline Symptomatic acquired AV block II t.1 & IIa & $\mathrm{C}$ \\
\hline \multicolumn{3}{|c|}{ Indications for continuous stimulation in patients with paroxysmal bradycardia } \\
\hline $\begin{array}{l}\text { Sick sinus syndrome (SSS) (brady-tachy syndrome, sinus } \\
\text { arrest, sinoatrial block) }\end{array}$ & I & $\mathrm{B}$ \\
\hline Paroxysmal AV block III & I & $\mathrm{C}$ \\
\hline Paroxysmal AV block II t.2 & I & $\mathrm{C}$ \\
\hline Atrial fibrillation with block & I & $\mathrm{C}$ \\
\hline $\begin{array}{l}\text { Reflex syncope and asystole in patients }>40 \text { years of age } \\
\text { with syncope and documented pauses in sinus arrest or } \\
\text { AV block, or both simultaneously }\end{array}$ & IIa & $\mathrm{C}$ \\
\hline $\begin{array}{l}\text { Asymptomatic sinus arrest, sinoatrial or AV block should } \\
\text { be considered in patients with a history of syncope and } \\
\text { recorded pauses of }>6 \text { sec. }\end{array}$ & IIa & $\mathrm{C}$ \\
\hline
\end{tabular}




\begin{tabular}{|c|c|c|}
\hline & $\begin{array}{l}\text { Class of } \\
\text { recommendation }\end{array}$ & $\begin{array}{l}\text { Level of } \\
\text { evidence }\end{array}$ \\
\hline \multicolumn{3}{|c|}{ Indications for cardiac stimulation in patients with bundle branch block (BBB) } \\
\hline $\begin{array}{l}\text { Bundle branch block in a patient with repeated } \\
\text { unexplained syncope and abnormal EPS test results }\end{array}$ & I & $\mathrm{B}$ \\
\hline Alternating bundle branch block & I & $\mathrm{C}$ \\
\hline \multicolumn{3}{|c|}{$\begin{array}{l}\text { Indications for implantation of an implantable cardioverter-defibrillator (ICD) - } \\
\text { primary prevention of SCD }\end{array}$} \\
\hline \multicolumn{3}{|l|}{$\begin{array}{l}\text { Symptomatic heart failure (II, III NYHA class) and } \\
\text { LVEF } \leq 35 \% \text { after } \geq 3 \text { months of optimal treatment, } \\
\text { if the expected life expectancy of the patient with good } \\
\text { functional status exceeds } 1 \text { year }\end{array}$} \\
\hline Ischaemic aetiology of heart damage & I & $\mathrm{A}$ \\
\hline Other aetiology & I & $\mathrm{B}$ \\
\hline \multicolumn{3}{|c|}{$\begin{array}{l}\text { Indications for implantation of an implantable cardioverter-defibrillator (ICD) - } \\
\text { secondary prevention of SCD }\end{array}$} \\
\hline $\begin{array}{l}\text { Past documented VF or instable haemodynamic VT with } \\
\text { no reversible cause treated optimally with life expectancy } \\
\text { of over } 1 \text { year with good functional status }\end{array}$ & I & A \\
\hline $\begin{array}{l}\text { Should be considered in patients with recurrent sustained } \\
\text { VT treated optimally, with normal LVEF with life } \\
\text { expectancy of over } 1 \text { year with optimal functional status }\end{array}$ & IIa & $\mathrm{C}$ \\
\hline \multicolumn{3}{|c|}{ Indications for implantation of a cardiac resynchronisation device (CRT/CRTD) } \\
\hline $\begin{array}{l}\text { LBBB with QRS duration }>150 \mathrm{~ms} \text { in patients with } \\
\text { chronic heart failure (II, III, ambulatory IV NYHA class) } \\
\text { and LVEF } \leq 35 \%\end{array}$ & I & A \\
\hline $\begin{array}{l}\text { LBBB with QRS duration }=120-150 \mathrm{~ms} \text { in patients with } \\
\text { chronic heart failure (II, III, ambulatory IV NYHA class) } \\
\text { and LVEF } \leq 35 \%\end{array}$ & I & $\mathrm{B}$ \\
\hline $\begin{array}{l}\text { QRS morphology not LBBB with QRS duration } \\
>150 \mathrm{~ms}\end{array}$ & IIa & $\mathrm{B}$ \\
\hline $\begin{array}{l}\text { QRS morphology not LBBB with QRS duration }=120- \\
150 \mathrm{~ms}\end{array}$ & $\mathrm{IIb}$ & $\mathrm{B}$ \\
\hline
\end{tabular}

SSS - sick sinus syndrome, AV - atrioventricular, BBB - bundle branch block, SCD - sudden cardiac death, ICD - Implantable Cardioverter-Defibrillator, NYHA - New York Heart Association, VF - ventricular fibrillation, VT - ventricular tachycardia, CRT/ CRTD - cardiac resynchronisation therapy, LBBB - left bundle branch block, EPS - electrophysiology study, LVEF - left ventricle ejection fraction 
Table 3. Selection of stimulation mode (Brignole et al., 2013)

\begin{tabular}{|l|l|c|c|}
\hline \multicolumn{1}{|c|}{ Indication for stimulation } & \multicolumn{1}{|c|}{ Type of stimulator } & Class & Level \\
\hline Sinus node dysfunction & $\begin{array}{l}\text { DDD } \\
\text { (second line - AAI pacemaker) }\end{array}$ & I & A \\
\hline Sinus node dysfunction & $\begin{array}{l}\text { DDD } \\
\text { (second line - AAI pacemaker) }\end{array}$ & I & A \\
\hline Sustained atrial fibrillation with AV block & VVI & I & C \\
\hline
\end{tabular}

DDD - dual chamber pacemaker; AAI - atrial single chamber pacemaker; VVI - ventricular single chamber pacemaker

The aim of this paper was to use classification trees for the selection of patients implanted with one of the three electrotherapy devices, i.e. SCVVI/AAI, DC-DDD, or ICD/CRT.

\section{Materials and Methods}

The analysis included 2071 patients that underwent implantation procedures or device replacement in the years 2010-2018, hospitalized in a cardiology department. An electronic database and hospital discharge summary reports were used.

The data was analysed with the use of classification trees. This method enables legible graphic presentation of the obtained results. It is also resistant to outliers, which are a common occurrence in medical data. For these reasons, among others, it is widely used in, e.g., astronomy (Salzberg et al., 1995), biology (Shmozono et al., 1994), and medicine (Judmaier et al., 1993; Milewska et al., 2016; Pouliakis et al., 2015). The process of building classification trees is based on recursive division (Breimanet et al., 1984). The set of characteristics is searched in order to find all the possible divisions into two parts so that both the obtained subsets would differ from each other in respect to the dependent variable at most. The division is repeated until uniform groups are obtained or until the algorithm stopping conditions are met (Wieczorek \& Świtała, 2008). CARTtype classification trees with 5-fold cross-validation were used for the analysis. Cross-validation makes it possible to avoid building an overfitting model. Statistica 13.0 (TIBCO Software INC) was used in the statistical analysis. 


\section{Results and Discussions}

In the analysed group, single chamber VVI/AAI were implanted in $33 \%$ of patients $(\mathrm{n}=690)$; dual chamber pacemaker DDD in $54 \%$ of patients $(\mathrm{n}=1107)$; whereas ICD/CRT, in $13 \%$ of patients $(\mathrm{n}=274)$.

The classification was created on the basis of the main indications for electrotherapy i.e. comorbidities, patient's age and sex (Figure 1). The main indications included: atrial fibrillation with AV block, AV block III, sinus node dysfunction, AV block II t.2, AV block 2:1, trifascicular block, AV block II t.1, alternating bundle branch block, cardiac arrest - primary prevention, and cardiac arrest - secondary prevention. Comorbidities: heart failure II and III NYHA class, hypertension, diabetes, chronic coronary syndrome, dilated and hypertrophic cardiomyopathy, atrial fibrillation, history of stroke, chronic obstructive pulmonary disease (COPD) chronic kidney disease, hyperthyroidism, and hypothyroidism.

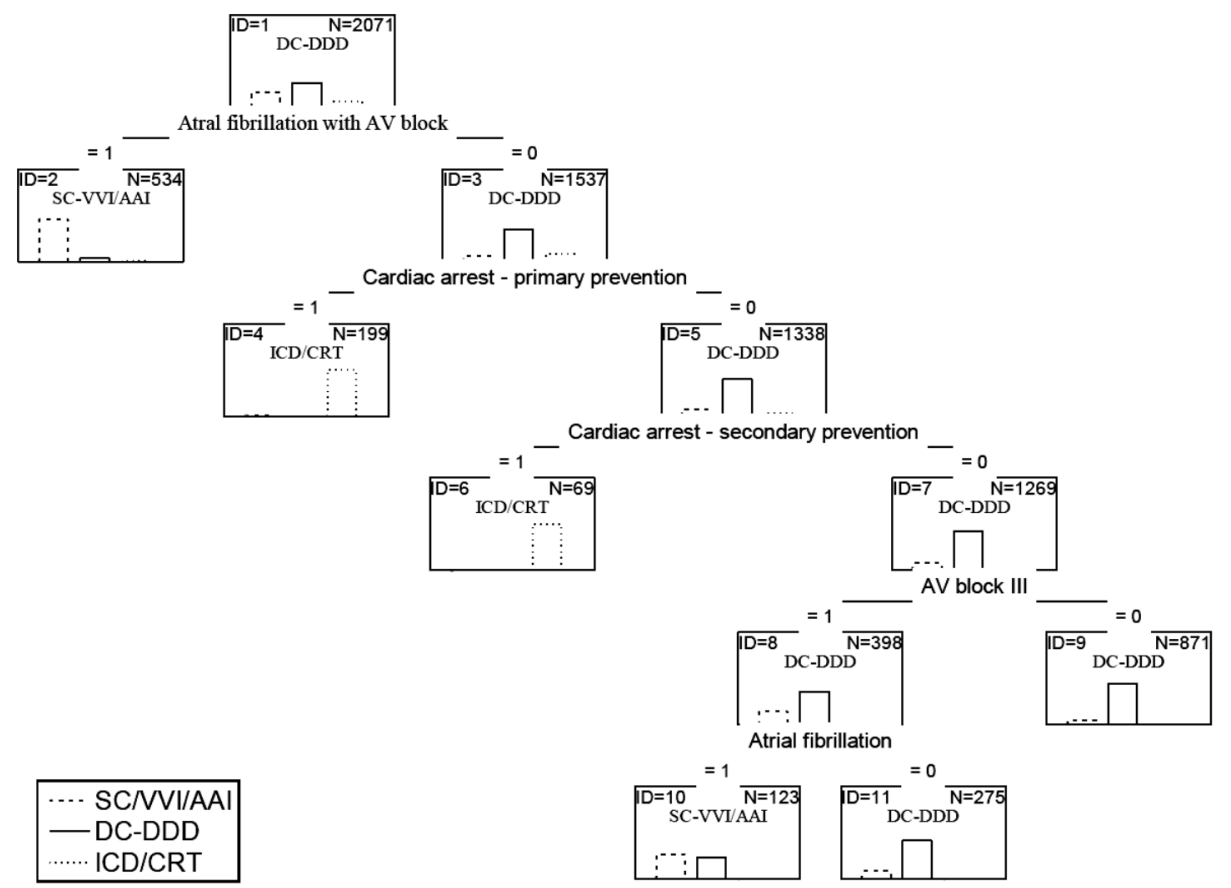

Figure 1. Classification tree

The tree was built on the basis of the following variables: atrial fibrillation with $\mathrm{AV}$ block (predictive value $=0.65$ ), cardiac arrest - primary prevention (predictive value $=1.0$ ), cardiac arrest - secondary prevention 
(predictive value $=0.60)$, AV block III (predictive value $=0.18)$, and atrial fibrillation (predictive value $=0.28$ ). The tree consisted of 5 nodes and 6 leaves.

Two leaves indicated the advantage of using SC-AAI/VVI (ID $=2$, $\mathrm{ID}=10)$. The first one $(\mathrm{ID}=2)$ concerned patients with atrial fibrillation with AV block, with the device implanted in 488 out of 534 of the cases $(91 \%)$. The patients indicated in leaf $\mathrm{ID}=10$ were characterized by the presence of AV block III and atrial fibrillation (atrial fibrillation with $\mathrm{AV}$ block did not occur; the indications: cardiac arrest - primary or secondary prevention were not present). In those patients, SC-AAI/VVI were implanted in 66 cases out of $123(54 \%)$.

The further two leaves indicated the advantage of using DC-DDD $(\mathrm{ID}=9, \mathrm{ID}=11)$. Leaf $\mathrm{ID}=11$ concerned patients with a history of AV block III (the indications: cardiac arrest - primary or secondary prevention were not present; atrial fibrillation with AV block did not occur; atrial fibrillation did not occur). In those patients, DC-DDD was used in 228 out of 275 cases $(83 \%)$. Leaf ID $=9$, on the other hand, describes patients in whom none of the indications were present: atrial fibrillation with AV block, cardiac arrest - primary or secondary prevention, AV block III). In those patients, DC-DDD was used in 782 cases out of 871 (90\%).

Two leaves also indicated the advantage of using ICD/CRT (ID $=4$, ID =6). The patients implanted with the device the most often were not diagnosed with atrial fibrillation with AV block but were referred because of "cardiac arrest - primary prevention" (ID $=4 ; \mathrm{n}=199 ; 100 \%$ of ICD/CRT choices) or because of "cardiac arrest - secondary prevention" (ID $=6$; $\mathrm{n}=69 ; 100 \%$ of ICD/CRT choices).

Atrial fibrillation with AV block and atrial fibrillation with AV block III are the classic indications for implantation of a single chamber pacemaker (SC-VVI). These concern the cases of patients with a history of sustained atrial fibrillation with slow ventricular conduction. According to the guidelines of the European Society of Cardiology (ESC) (Brignole et al., 2013), this is an IC class recommendation. In the presented study, $91 \%$ of the patients with the indication in question had the device implanted.

A typical indication for implantation of a DDD pacemaker is sinus rhythm with AV block III. $83 \%$ of patients in this group had this device implanted. The ESC recommendation in these cases leaves no doubt (IC). In the case of sick sinus syndrome, AV block II t.2, symptomatic AV block t.1, and symptomatic AV block 2:1, a preferred device is also the dual chamber pacemaker (DC-DDD). In the presented 
analysis, $90 \%$ of patients with these disorders were treated with this method.

Asynchronous stimulation, i.e. only of the right ventricle (VVI), as opposed to synchronous right atrium-right ventricle (DDD), increases the risk of the occurrence and sustenance of atrial fibrillation, which is haemodynamically unfavourable, increasing the risk of heart failure (Mulpuru et al., 2017).

Implantable cardioverters-defibrillators (ICD) and/or cardiac resynchronization devices with defibrillator function (CRTD) are used when clinical indications are met (symptomatic heart failure) accompanied by serious systolic left ventricle dysfunction $(\mathrm{LVEF} \leq 35 \%)$. The patient must be treated optimally (in accordance with the ESC guidelines concerning chronic heart failure) and be characterized with a good 12-month survival prognosis (in primary prevention - recommendation IA or IB depending on the aetiology of heart damage). In secondary prevention the recommendation is unambiguous - IA. It is similarly unambiguous in the case of paroxysmal ventricular tachycardia (VT) - IIa with level of evidence C. In the presented analysis, $100 \%$ of patients with the aforementioned indications had devices implanted that improved prognosis (ICD, CRTD) (Ponikowski et al., 2016).

The type of the stimulating device used is connected with type of impulse generation and/or atrioventricular conduction disturbances, regardless of the underlying cause (if they are not the result of a reversible cause, e.g. electrolyte disturbances) (Brignole et al., 2013). In the case of an implantable cardioverter-defibrillator (ICD) implanted as secondary prevention, the indications result from a history of cardiac arrest in the course of ventricular fibrillation (VF) regardless of the aetiology (provided that the causes are not reversible, e.g. acute ischaemia) or in the case of recurrent, life-threatening ventricular arrhythmia (Ponikowski et al., 2016).

In primary prevention, ICD/CRTD implantation is connected with the primary disease, i.e. symptomatic chronic heart failure with additional echocardiographic indications, the implemented therapy, or depends on the patient's prognosis. Guidelines concerning the indications for such treatment to be used differentiate between ischaemic and non-ischaemic (dilated cardiomyopathy) causes of heart damage. The indications only differ in the level of evidence at the same class of recommendation. In a significant number of patients, the aetiology of left ventricular muscle. In some patients, both aetiologies of heart damage (ischaemic and non-ischaemic) may be present simultaneously (Ponikowski et al., 2016). 


\section{Conclusions}

Electrotherapy is a dynamically developing method of treatment of impulse generation and/or atrioventricular conduction disturbances. It is an extremely important method used in heart failure treatment. The guidelines that include indications for implantation of devices are periodically updated as medical knowledge and technologies develop. They are an incredibly valuable source that help to make optimal decisions in various clinical states. The decision concerning the choice of a particular device is always taken on the basis of the current recommendations and the patient's clinical condition. The used classification trees may enable verification of the state of implementation of guidelines for electrotherapy on real-life therapeutic decisions. Using devices of this type may have a positive impact in the process of making correct therapeutic decisions.

\section{R E F E R E N C E S}

Breiman, L., Friedman, J., Olshen, R., \& Stone, C. (1984). Classification and Regression Trees. Wadsworth Publishing, CA.

Brignole, M., Auricchio, A., Baron-Esquivias, G., Bordachar, P., Boriani, G., Breithardt, O., Cleland, J., Deharo, J-C., et al. (2013). ESC Guidelines on cardiac pacing and cardiac resynchronization therapy: the Task Force on cardiac pacing and resynchronization therapy of the European Society of Cardiology (ESC). Developed in collaboration with the European Heart Rhythm Association (EHRA). European Heart Journal, 34(29), 2281-2329. doi: 10.1093/eurheartj/eht150.

Judmaier, J., Meyersbach, P., Weiss, G., Wachter, H., \& Reibnegger, G. (1993). The role of Neopterin in assessing disease activity in Crohn's disease: Classification and regression trees. The American Journal of Gastroenterology, 88(5), 706-711.

Milewska, A. J., Jankowska, D., Cwalina, U., Citko, D., Więsak, T., Acacio, B., \& Milewski, R. (2016). Prediction of infertility treatment outcomes using classification trees. Studies in Logic, Grammar and Rhetoric. Logical, Statistical and Computer Methods in Medicine, 47(60), 7-19. doi: 10.1515/slgr2016-0043

Mulpuru, S., Madhavan, M., McLeod C. J., Cha, Y. M., \& Friedman, P. A. (2017). Cardiac Pacemakers: Function,Troubleshooting, and Management: Part 1 of a 2-Part Series. Journal of the American College of Cardiology, 69(2), 189-210. doi: 10.1016/j.jacc.2016.10.061

Ponikowski, P., Voors, A. A., Anker, S. D., Bueno, H., Cleland, J., Coats, A., Falk, V., González-Juanatey, J. R. et al. (2016). ESC Guidelines for the diagnosis and treatment of acute and chronic heart failure: The Task Force for 
the diagnosis and treatment of acute and chronic heart failure of the European Society of Cardiology (ESC) Developed with the special contribution of the Heart Failure Association (HFA) of the ESC. European Heart Journal, 37(27), 2129-2200. doi: 10.1093/eurheartj/ehw128

Pouliakis, A., Karakitsou, E., Chrelias, C., Pappas, A., Panayiotides, I., Valasoulis, G., Kyrgiou, M., et al. (2015). The Application of Classification and Regression Trees for the Triage of Women for Referral to Colposcopy and the Estimation of Risk for Cervical Intraepithelial Neoplasia: A Study Based on 1625 Cases with Incomplete Data from Molecular Tests. BioMed Research International, 2015, 914740.

Salzberg, S., Chandar, R., Ford, H., Murthy, S., \& White, R. (1995). Decision Trees for Automated Identification of Cosmic-Ray Hits in Hubble Space Telescope Images. Publications of the Astronomical Society of the Pacific, 107(709), 279-288.

Shimozono, S., Shinohara, A., Shinohara, T., Miyano, S., Kuhara, S., \& Arikawa, S. (1994). Knowledge acquisition from amino acid sequences by machine learning system BONSAI. Transactions of the Information Processing Society of Japan, 35(10), 2009-2018.

Wieczorek, T., \& Świtała, P. (2008). Wykorzystanie algorytmu CART do automatycznego tworzenia bazy wiedzy systemu ekspertowego. In S. Kozielski, B. Małysiak, P. Kasprowski, \& D. Mrozek (Eds.), Bazy Danych: Rozwój metod $i$ technologii. WKE. 